\title{
Photovoltaic greenhouses: evaluation of shading effect and its influence on agricultural performances
}

\author{
Sergio Castellano \\ Department of Science of Agriculture, Food and Environment, University of Foggia, Italy
}

\begin{abstract}
During the last years, European government remuneration polices promoted the realisation of photovoltaic systems integrated with the structures instead of on ground photovoltaic (PV) plants. In this context, in rural areas, greenhouses covered with PV modules have been developed. In order to interdict the building of greenhouses with an amount of opaque panels on covering not coherent with the plant production, local laws assigned a threshold value, usually between $25 \%$ and $50 \%$, of the projection on the soil of the roof. These ranges seem not to be based on scientific evaluation about the agricultural performances required to the building but only on empirical assessments. Purpose of this paper is to contribute to better understand the effect of different configurations of $\mathrm{PV}$ panels on the covering of a monospan duo-pitched roof greenhouse in terms of shading effect and energy efficiency during different periods of the year. At this aim, daylighting and insolation analysis were performed by means of the software Autodesk ${ }^{\circledR}$ Ecotect $^{\circledR}$ Analysis (Autodesk, Inc., San Rafael, CA, USA) on greenhouse model with different covering ratio of polycrystalline photovoltaic panels on the roof.
\end{abstract}

\section{Introduction}

Photovoltaic (PV) installations are quickly increasing in Europe and in Italy during last ten years. The energetic production from PV panels increased in Europe from almost $1 \mathrm{GW}$ in 2004 to $88 \mathrm{GW}$ in 2013, in the same period in Italy it passed from almost $0.1 \mathrm{GW}$ to $18 \mathrm{GW}$ (EPIA, 2014). The expansion of the PV sector - and more in general of the

Correspondence: Sergio Castellano, Department of Science of Agriculture, Food and Environment (SAFE), University of Foggia, via Napoli 25, 71100 Foggia, Italy.

E-mail: sergio.castellano@unifg.it

Key words: photovoltaic greenhouses, daylight, shading, illuminance.

Received for publication: 4 August 2014.

Accepted for publication: 19 September 2014.

(C) Copyright S. Castellano, 2014

Licensee PAGEPress, Italy

Journal of Agricultural Engineering 2014; XLV:433

doi:10.4081/jae.2014.433

This article is distributed under the terms of the Creative Commons Attribution Noncommercial License (by-nc 3.0) which permits any noncommercial use, distribution, and reproduction in any medium, provided the original author(s) and source are credited. renewable sources sector - is due mainly to the advantageous remuneration policies available in various Countries (Sarasa-Maestro et al., 2013; Badcock and Lenzen, 2010). Over the last years, in Italy, an exponential growth of PV industry, involving also the primary sector through the realisation of PV systems on ground or buildings has been registered (Tudisca et al., 2013). In rural landscapes, due to the consumption of land and to the environmental and biodiversity impacts involved by on ground PV plants (Beylot et al., 2011, Taylor, 2014), government remuneration polices promoted the realisation of integrated PV systems with the structures instead of on ground PV plants (GSE, 2013). In this context, greenhouses covered with PV modules have been developed during last years. In 2012 almost the $6 \%$ of energy produced by PV panels in Italy (16420 MW) were installed on greenhouses and shelters (GSE, 2013). The main challenge for these mixed systems is to gain higher productiveness with respect to the quality and to obtain a lower impact on environment than both systems implemented in an independent area (Poncet et al., 2012). On the one hand the placement of PV modules on greenhouse takes advantage from the large surface available and avoids the heavy debate on the destination of land use because, unlike the ground systems, it does not subtract area for the cultivation of agricultural products for very long periods (almost thirty years) and it does not compromise the soil fertility (Vieri, 2012), moreover, in same period of the year - especially in Mediterranean region - shading systems are required and the activities are suspended during the summer (Marucci et al., 2013). On the other hand, the area of PV modules will intercept the photosynthetically active radiation (PAR) necessary for crop production and- except for specific requirements such shading systems or mushroom farms- it is in contrast with the main function of the greenhouse which is to optimise solar radiation transmission under controlled conditions, to improve the growing environment (EN13031-01, 2001; Vox et al., 2010). It is strategic to find a balance between two opposite needs: reduce the shading effect in order to allow as much as possible the PAR component entering into the greenhouse (Schettini et al., 2011) and improve the energy production which is proportional to the opaque surface of the panels (Vox et al., 2008). The greenhouse design optimisation including photovoltaic panels, the development of more transparent solar panels (Yano et al., 2014), and the selection of plants adapted to this particular system of production represent three technological research areas that shall be developed in the near future (Poncet et al., 2012).

In order to interdict the building of greenhouses with an amount of opaque panels on covering not coherent with the plant production, local laws assign a threshold value, usually the $25-50 \%$ of the projection on the soil of the roof. These ranges seem not to be based on scientific evaluation about the agricultural performances required to the building but only on empirical assessments. Purpose of this paper is to contribute to better understand the effect of different configurations of PV panels on the covering of a monospan duo-pitched roof greenhouse in terms of shading effect and energy efficiency during different period of the year. 


\section{Materials and methods}

Daylighting and insolation analysis inside different models of photovoltaic greenhouses were performed by means of the software Autodesk $^{\circledR}$ Ecotect $^{\circledR}$ Analysis (Autodesk, Inc., San Rafael, CA, USA) (Autodesk, 2011).

\section{Greenhouse models}

A commercial duo-pitched roof steel glasshouse was used in simulations: span $s=10.00 \mathrm{~m}$, length $\mathrm{l}=32.00 \mathrm{~m}$, distance between frames $\mathrm{d}=3.20$ $\mathrm{m}$; height of the gutter $\mathrm{hg}=3.00 \mathrm{~m}$, height of the ridge $\mathrm{hr}=5.00 \mathrm{~m}$, roof slope $22^{\circ}$. Supporting steel elements were designed by means of structural code EN13031-1, hypothesising Rome - coordinates $41.8^{\circ} \mathrm{N}, 12.6^{\circ} \mathrm{E}$ - as building site location: column and beams steel rectangular pipes $40 \times 100 \times 4$ $\mathrm{mm}$, secondary elements steel circular pipes $\mathrm{f}=33 \mathrm{~mm} \mathrm{t}=2 \mathrm{~mm}$ (Figure 1 ). In calculations, a minimum working life of 30 years was assumed. The glasshouse was E-W oriented and PV panels were settled on southern pitched roof. Polycrystalline silicon PV panels $1.00 \times 1.60 \mathrm{~m}$, were considered in calculations. For the purpose of Ecotect Analysis was assumed: glass transmissivity $\tau_{\mathrm{g}}=0.95$, internal surface of PV panels made in plastic with an high reflective colour (white) assuming reflectivity $\rho_{\mathrm{p}}=0.81$, concrete floor with reflectivity $\rho_{p}=0.55$. Moreover, it was assumed a reduction of transmissivity of $90 \%$ taking into account the effect of accumulation of dirty on the surface. A grid - 7 rows per 22 columns - of points within the model at which light, solar insolation, can be calculated and displayed was considered in the model. The reference plane, on which results were gathered, was horizontal and parallel to the floor of the greenhouse at $10 \mathrm{~cm}$ from the ground (Figures 1 and 2). The reference plane was divided into 8 zones - Z1/Z2/... Z8 - in order to appreciate the effect of shading in different areas of the greenhouse (Figure 2). Different PV panels covering ratio (CR) were considered: greenhouse $A(\mathrm{G}-\mathrm{A})$ was the control model without $\mathrm{PV}$ panels on the roof and $\mathrm{CR}=0 \%$ (Figure $3 \mathrm{~A}$ ); PV greenhouse $B$ (PVG- B) with $\mathrm{CR}=20 \%$ (Figure 3B-D), PV greenhouse $C$ (PVG- C) with $\mathrm{CR}=30 \%$ (Figure 3E), PV greenhouse $D$ (PVG- D) with $\mathrm{CR}=50 \%$ (Figure $3 \mathrm{~F}$ ). The covering ratio is defined as the ratio, expressed in percent, between the projection on the ground of the surface of the PV panels installed on the roof and the surface of the projection on the ground of the whole roof. Three different configurations for $\mathrm{CR}=20 \%$ were considered: PVG- B1 two lines of PV panels, alternate with glass panels; PVG- B2 two adjacent lines of PV panels at ridge level; PVG- B3 two adjacent lines of PV panels at gutter level (Figure 3). Data resulting for PVG- B refers to the average results calculated for PVG- B1, PVG- B2, PVG- B3.

\section{Daylighting}

Daylight refers to the level of diffuse natural light coming from the whole sky dome or reflected off nearby surfaces to provide illumination for internal spaces within a building. While the main source of natural light is the Sun itself, atmospheric scattering and reflection of clouds means that the entire sky also emits light. For the purposes of daylighting design, the sky is considered as a large hemispherical surface, or dome, completely surrounding each building or space. Daylight factor (DF) is defined as the ratio of the illuminance at a particular point within an enclosure to the simultaneous unobstructed outdoor illuminance under the same sky conditions, expressed as a percentage. Illuminance (lux) is the total luminous flux incident on a surface, per unit area. The position of the sun in the sky varies continuously, since it is dependent on the geographical location of the site (latitude and longitude) on the time of the day and the period of the year. Sunlight is also subject to significant changes due to sky conditions (e.g., clouds), obstructions, levels of pollution, etc. The distribution of daylight from the sky dome depends on weather conditions. Clear skies tend to be brighter in the proximity of the horizon, while overcast skies have higher luminance values at the zenith. To account for this, basing on the analysis of climate statistics, the Commission International de l'Eclairage (CIE) has defined a series of sky models accounting for different luminance distribution: clear sky; intermediate sky; isotropic sky; overcast sky (CIE, 1996). Ecotect assumes CIE Overcast sky model day in which the majority of light comes from the zenith of the sky (up to three times more than at the horizon) (Autodesk, 2011). The model is independent of time due to the fact that the variation is only with altitude of the light source over the sky dome. Thus, DF in a space will not vary with orientation as there is no sun visible in the sky, it is assumed to be all diffuse light. The design sky is given as an illuminance level that is exceeded $85 \%$ of the time during the hours of 9 a.m. to 5 p.m. throughout the working year. The design sky value depends only by the latitude of the site (Tregenza and Waters, 1983). Using this value, it is possible to convert a DF into an illuminance level by simply multiplying the two. Thus, for instance, a point with a daylight factor of $10 \%$ at a location with a design sky value of 5000 lux will likely have an illuminance level of at least 500 lux 85\% of the time (Autodesk, 2011).

\section{Insolation}

Insolation is the amount of incident solar radiation that falls upon a surface - in our case data are gathered on plane parallel to the floor inside the greenhouse at $10 \mathrm{~cm}$ from the ground. It is calculated in Watts per square meter $\left(\mathrm{W} / \mathrm{m}^{2}\right)$ and refers to the wide spectrum radiant energy from the sun which strikes an object or surface within the Ecotect model. This includes both a direct component from the sun itself (sunshine) and a diffuse component from the visible sky (skylight). All components are calculated directly from the geometry of the model as well as from hourly direct and diffuse solar radiation. It is important to note that insolation refers only to the amount of energy actually falling on a surface, which is

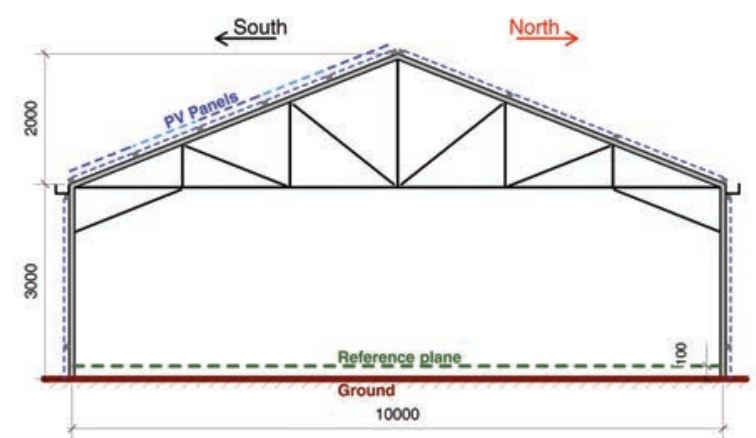

Figure 1. Main frame section of greenhouse models measures in millimetres. PV, photovoltaic.

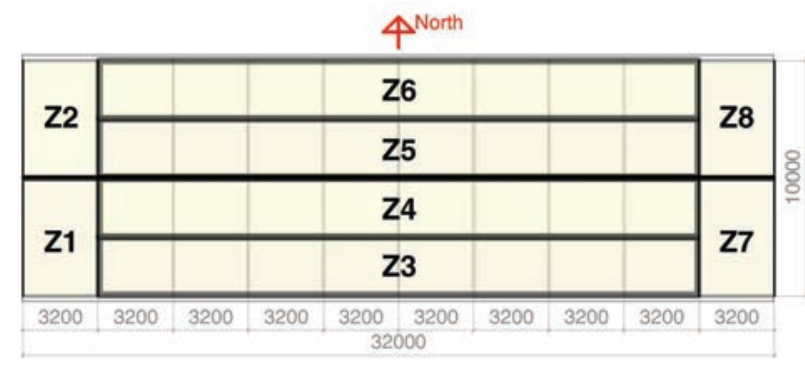

Figure 2. Identification of zones, $\mathrm{Z1}, \mathrm{Z2}, \ldots \mathrm{Z8}$ on the reference plane, measures in millimetres. 
not affected in any way by the surface properties of materials or by any internal refractive effects. External shading in Ecotect is calculated using shading masks. A shading mask stores the percentage in shade of any surface at a range of sky angles. The mask is used in the calculation of both diffuse and beam components (direct). For the beam component, the position of the sun is first calculated at the required date and time. This gives the sun position in the sky expressed by azimuth and altitude which can be used to locate a specific cell in the mask which stores the percentage of the object that is in shade from that angle. From this shading percentage an exposure value is calculated from, which is then multiplied by the beam component. As the distribution of diffuse light over the sky dome can vary very quickly as clouds gather and disperse, it is not possible to accurately model over any period exactly where in the sky the majority of radiation is coming from - thus Ecotect assumes a uniform distribution of diffuse radiant energy. Thus, to calculate the diffuse factor, the area-weighted (or in this case solid angle) exposure value over the entire sky dome is used (Autodesk, 2011). For all investigated PV greenhouses models, the shading percentage (PS), or the complementary value defined as exposed percentage (PE), was calculated (from 8.00 a.m. to 17.00 p.m.) along four representative days of the year: March 14, June 14, September 14 and December 14. Was chosen the half of the months of December due to the winter solstice which marks the day of the year with the least hours of daylight, June for the summer solstice which marks the day of the year with the most hours of daylight, March and September due to the equinoxes when the sun shines directly on the equator and the length of day and night is nearly equal.
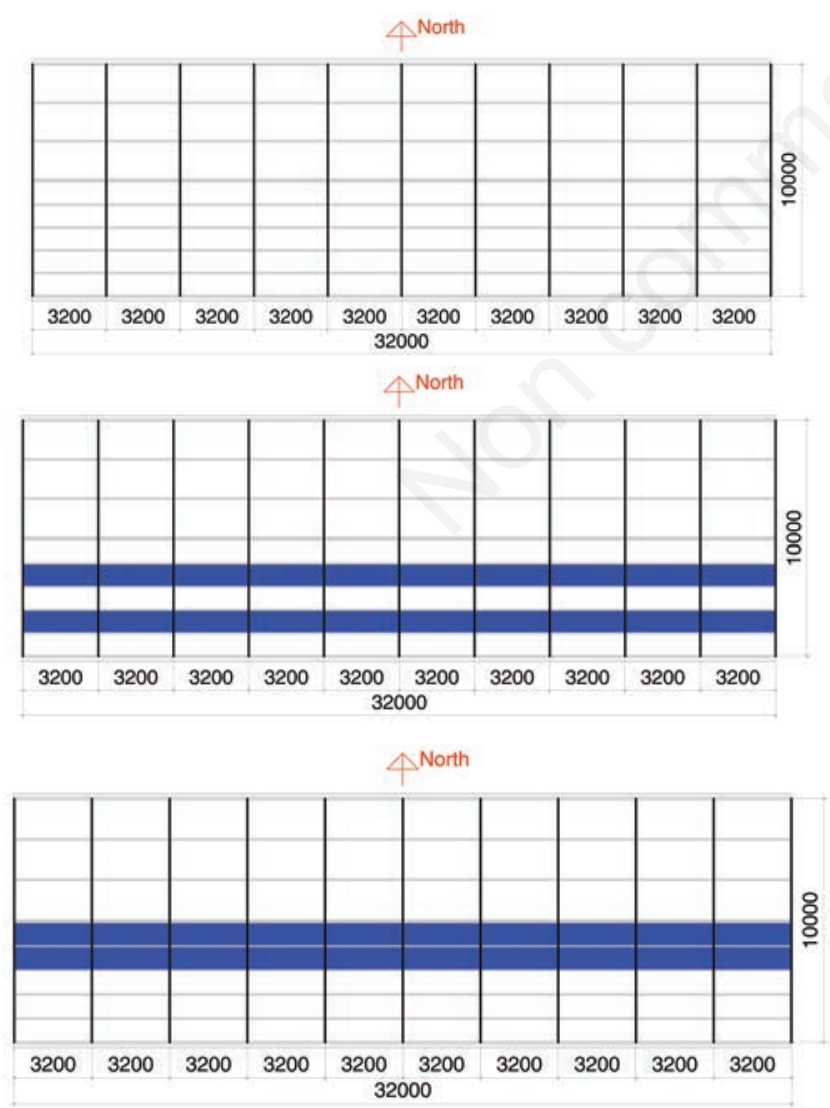

\section{Results and discussion}

As it was expected, the DF inside the structure decreases with the increasing of the PV covering on the roof passing from the $71.4 \%$ for the greenhouse G- A (CR=0\%) to the $50.0 \%$ for the PVG- D (CR=50\%) (Figure 4). As shown in Figure 5A, the correlation between CR and DF is linear and can be described by the Equation 1:

$\mathrm{DF}=0.4262 \mathrm{CR}+70.954$

also the variation of daylight factor $(\Delta \mathrm{D})$ calculated in different models with respect to the greenhouse without PV panels and CR (Figure 5B) can be described by a linear function (Eq. 2).

$\Delta \mathrm{D}=0.4379 \mathrm{CR}$

in which:

$\Delta \mathrm{D}_{\mathrm{i}}=\mathrm{DF}_{\mathrm{PVG}-\mathrm{i}}-\mathrm{DF}_{\mathrm{G}-\mathrm{A}}$;

$\mathrm{i}=\mathrm{A}, \mathrm{B}, \mathrm{C}, \mathrm{D}$.

Coefficients in Equations 1 and 2 are affected by the geometry of the structure especially with regard to the height of columns, by the site location and by the position of the horizontal plane on which are calculated the values. In G- A, CR=0 and consequently DF=70.954\% (Eq. 1), meaning that the shading effect of the structure and of the covering on the reference plane is nearby the $29 \%$. Daylight decreases with increasing of covering ratio (Eq. 1) even if the reduction is less than proportional (Eq. 2).
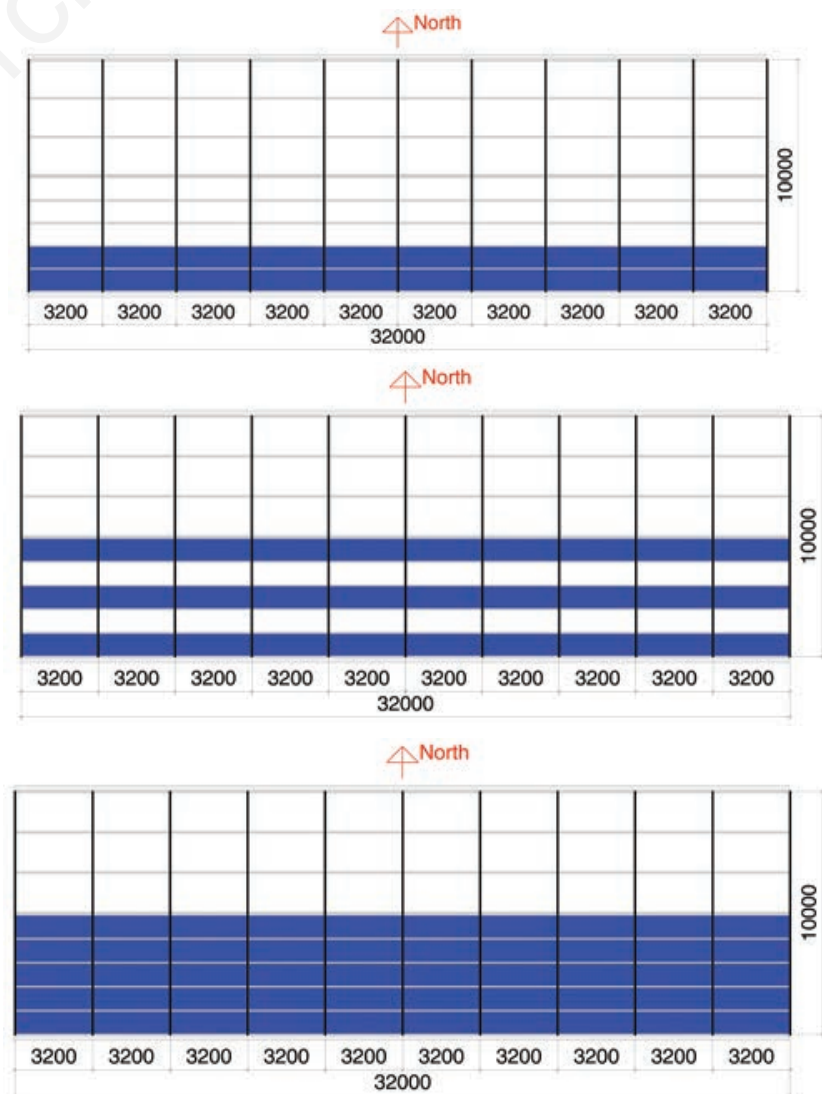

Figure 3. Covering layout of tested models with different covering ratio: G- A (A); PVG- B1 (B); PVG- B2 (C); PVG- B3 (D); PVG- C (E); PVG- D (V). In blue photovoltaic panels on coverings. 
Figure 4 shows a wide variation of results in different zones of the greenhouses highlighting that the average value recorded on the whole reference plane could not adequately represent the performance of the structure. In the zones next to the gable walls of tested greenhouses, daylight factor is higher in west exposed zones Z1 and Z2, then in the eastern one Z3 and Z4. This result could induce to prefer the eastern front of the greenhouse for the service lane and to provide for cultivations on the opposite zones where is higher the daylight. Into the intermediate zones Z3, Z4, Z5, Z6 where cultivations take place, in all investigated cases, DF increases passing from south (Z3) to north (Z6) even if DF differences between investigated models decrease passing from

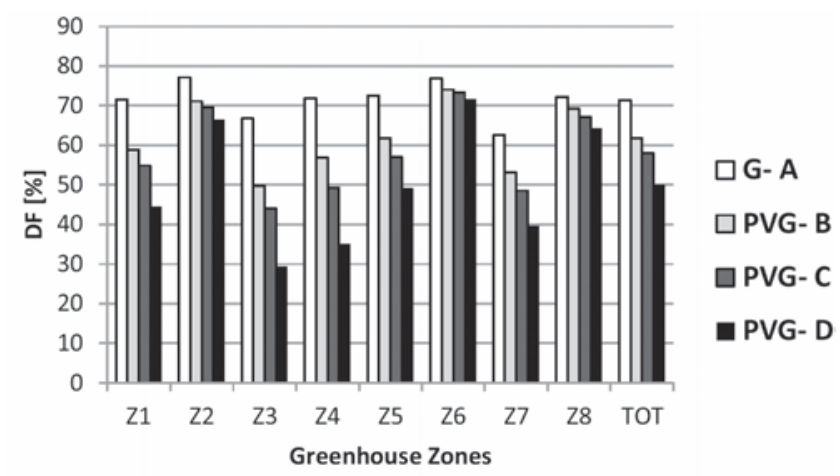

Figure 4. Daylight factor (DF) calculated with respect to the entire surface (TOT) and to the eight zones $(\mathrm{Z1}, \mathrm{Z2}, \ldots, \mathrm{Z8})$ on reference plane in G- A (CRA $=0 \%)$, PVG- B $(C R B=20 \%)$, PVG$\mathrm{C}(\mathrm{CRC}=30 \%)$, PVG- D (CRD $=50 \%)$.
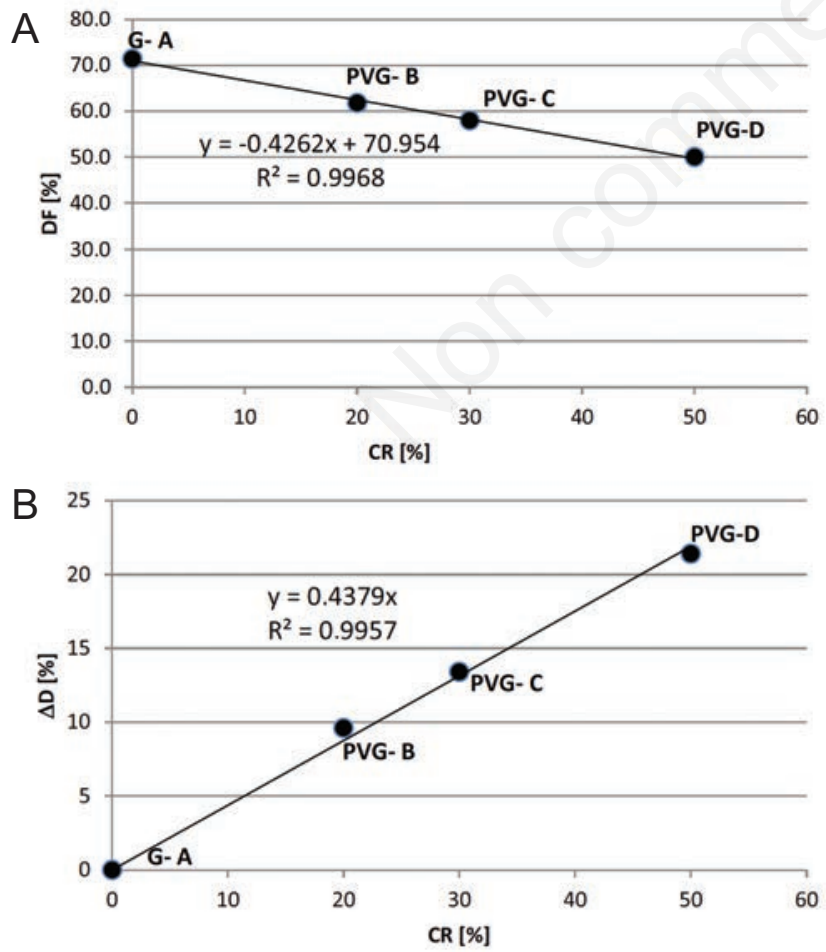

Figure 5. Correlation between the covering ratio (CR) with the daylight factor $(A)$ and with the variation of daylight $(\Delta D)$ of different tested models with respect to the greenhouse without photovoltaic (PV) panels (B).
Z3 to Z6 (Figure 4). This result is probably due to the CIE overcast (CIE, 1996) sky model assumed by Ecotect in which the majority of light comes from the zenith of the sky (up to three times more than at the horizon) (Autodesk, 2011). Zones Z3 and Z4 show very low values of daylight, generally lower than $50 \%$, the lower value $29 \%$ is calculated in Z3 of PVG- D (Figure 4). The distribution of daylight factor in different zones of the three investigated configurations (PVG- B1, PVG- B2, PVGB2) with $\mathrm{CR}=20 \%$ are shown in Figure 6 . The behaviour of DF is almost the same shown in Figure 7 except for the PVG- B3 in which the daylight shows a parabolic variation from south (Z3) to north (Z6) with higher values on zones Z3 (DF=59\%) and Z6 (DF=73\%) and lower on

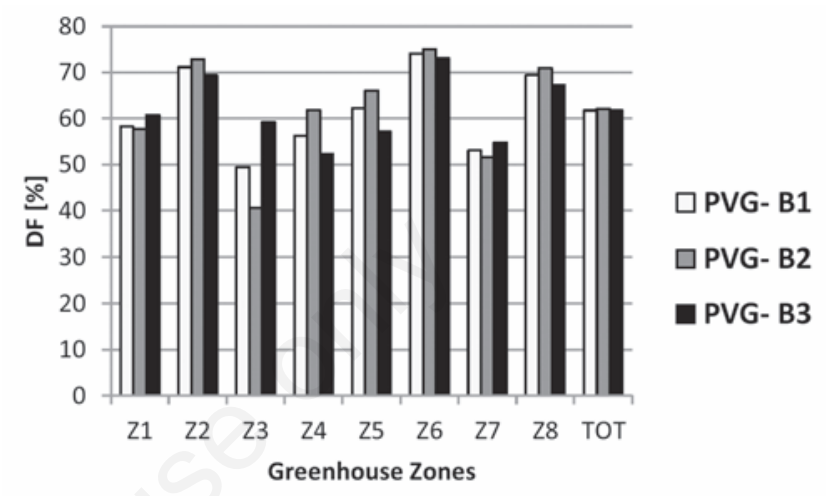

Figure 6. Daylight factor (DF) calculated with respect to the entire surface (TOT) and to the eight zones $(\mathrm{Z1}, \mathrm{Z2}, \ldots, \mathrm{Z8})$ on reference plane of photovoltaic (PV) greenhouse with a covering percentage of $20 \%$ in three different configurations (PVG- B1, PVG- B2, PVG- B3).
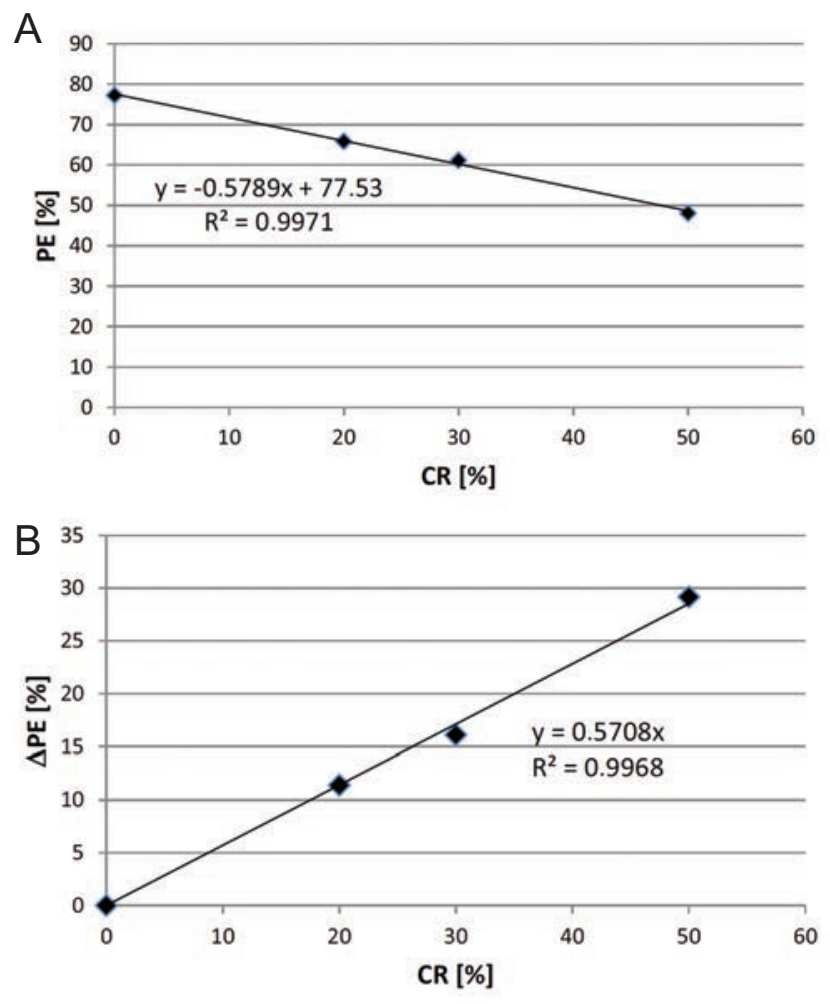

Figure 7. Correlation between the covering ratio (CR) with the percentage exposed (PE) (A) and with the variation of percentage exposed $(\triangle \mathrm{PE})(\mathrm{B})$. 
intermediate zones Z4 (DF=52\%) and Z5 (DF=58\%). The lower value is calculated in $\mathrm{Z3}(\mathrm{DF}=40 \%)$ for PVG- $\mathrm{B} 2$ even if the best performance in terms of daylight are calculated for the same configuration in zones $\mathrm{Z} 4(\mathrm{DF}=62 \%), \mathrm{Z} 5(\mathrm{DF}=66 \%)$ and $\mathrm{Z6}(\mathrm{DF}=74 \%)$. The calculated $\mathrm{DF}$ on the whole surface of the reference plane is almost the same for the three configurations (Figure 7).

Insolation analysis allowed calculating PS on the reference plane and its complementary value PE. Analysis results depend on the sun position and were calculated with regard to four representative days of the year (14 March, 14 June, 14 September, 14 December) and to the yearly average value. The PE value yearly average values showed a linear correlation with the covering ratio (Figure 7A):

$\mathrm{PE}=0.5789 \mathrm{CR}+77.53$

also the relationship between the variation of PE ( PE) with respect to the greenhouse without PV panels and the CR is described by a linear function (Figure 7B).

$\Delta \mathrm{PE}=0.5708 \mathrm{CR}$

where:

$\Delta \mathrm{PE}=\mathrm{PE}_{\mathrm{PVG}-\mathrm{i}}-\mathrm{PE} \mathrm{E}_{\mathrm{G}-\mathrm{A}} ;$

$\mathrm{i}=\mathrm{A}, \mathrm{B}, \mathrm{C}, \mathrm{D}$.

In $\mathrm{G}-\mathrm{A}$, on which there are not PV panels, $\mathrm{CR}=0$ and consequently $\mathrm{PE}=77.53 \%$ (Eq. 3), meaning that the shading effect of the structure and of the covering on the reference plane is nearby the $22.5 \%$, lower than the same value calculate with daylight analysis (Eq. 1). PE decreases with increasing of covering ratio (Eq. 1) even if the reduction is less than proportional (Eq. 2). The global behaviour of daylight factor (Eq. 1) and of percentage exposed (Eq. 3) with respect to cover-
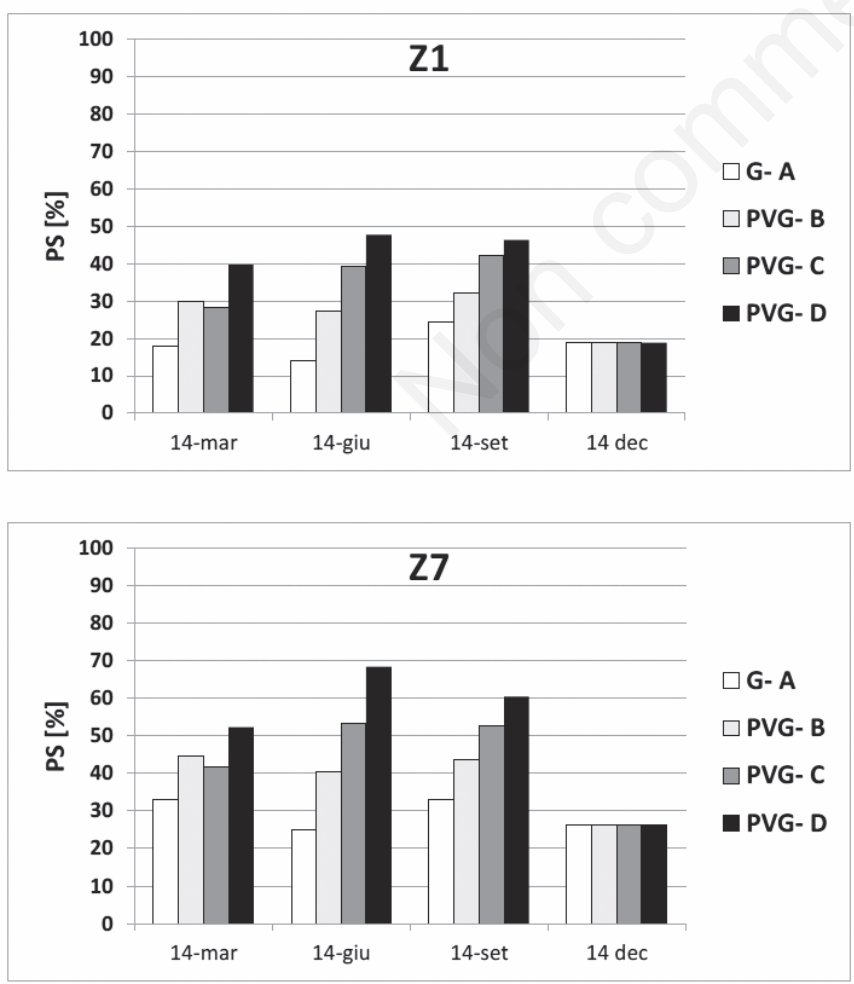

ing ratio is very similar. Even if DF and $\mathrm{PE}$ are not comparable quantity the variation of PE during different period of the year could be used to appreciate the variation of DF during the same period.

Insolation analysis allowed investigating the variability of results not only in different moment of the year but (Figure 8) also in different zones of the greenhouse (Figures 9 and 10). In both cases results show like daylight factors that average cumulative value could not be always representative of the performances of the greenhouses.

Concerning the influence of sun position, Figure 8 highlights that lower values of PS are calculated in December due to the low sun position on the horizon, highest values are registered on March or

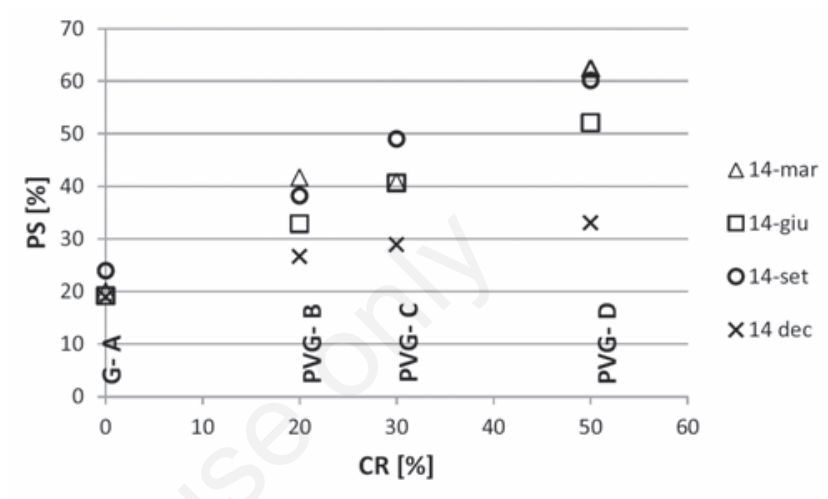

Figure 8. Correlation between the covering ratio (CR) and percentage shaded (PS) calculated in four representative days from 8.00 a.m. to 17.00 p.m. in tested greenhouses.
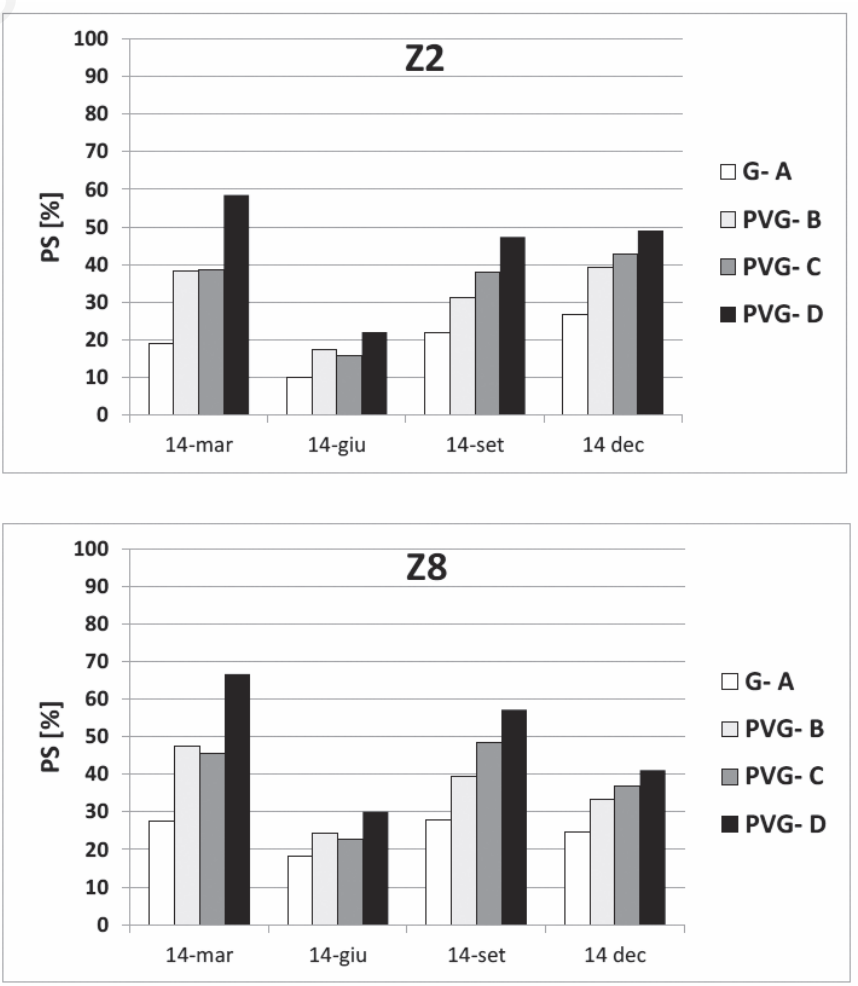

Figure 9. Percentage shaded (PS) in zones Z1-Z2 (west) Z7-Z8 (east) of tested greenhouses in four representative days from 8.00 a.m. to 17.00 p.m. 

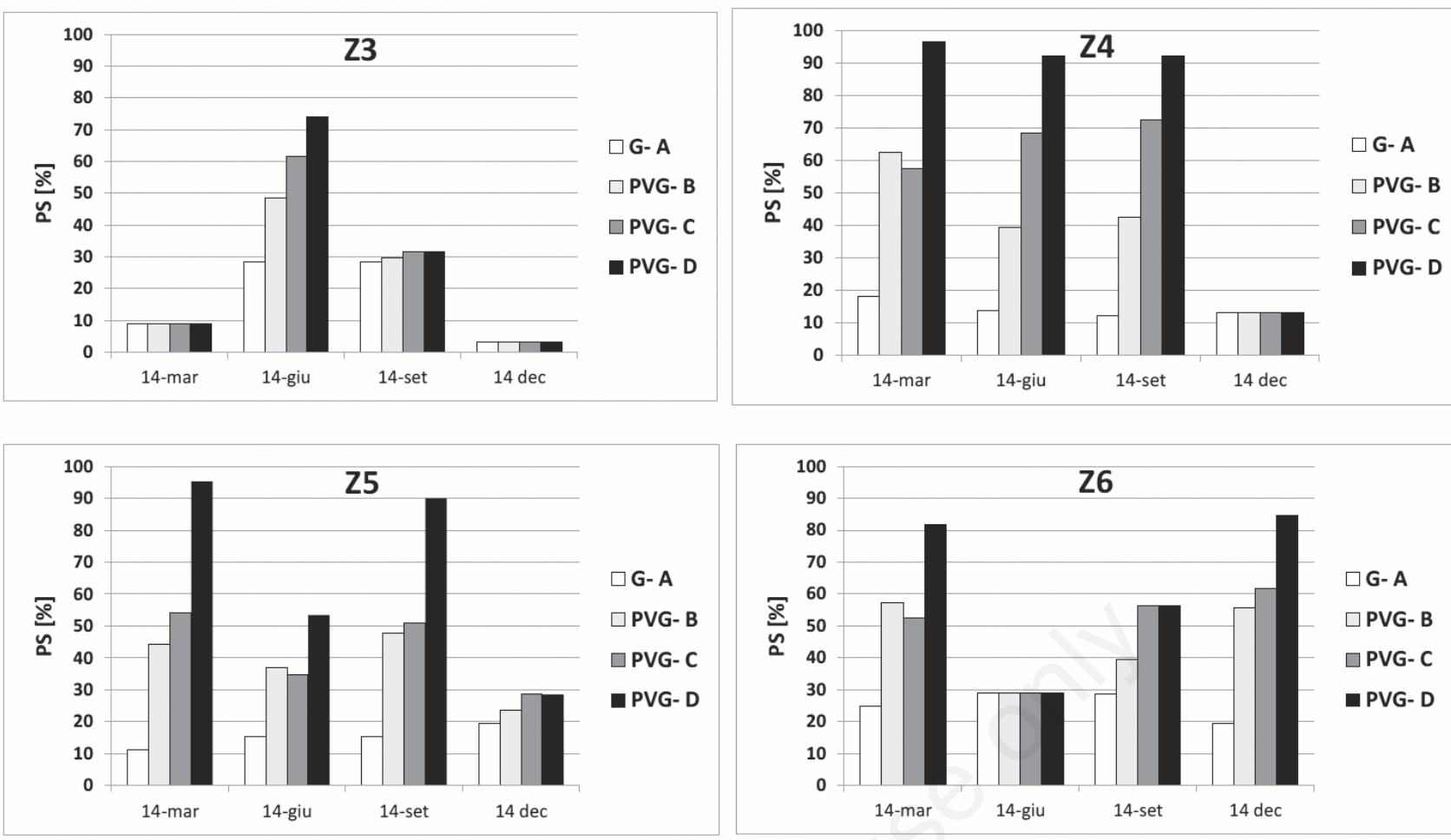

Figure 10. Percentage shaded (PS) in zones Z3 (south)-Z4-Z5-Z6 (north) of tested greenhouses in four representative days from 8.00 a.m. to 17.00 p.m.
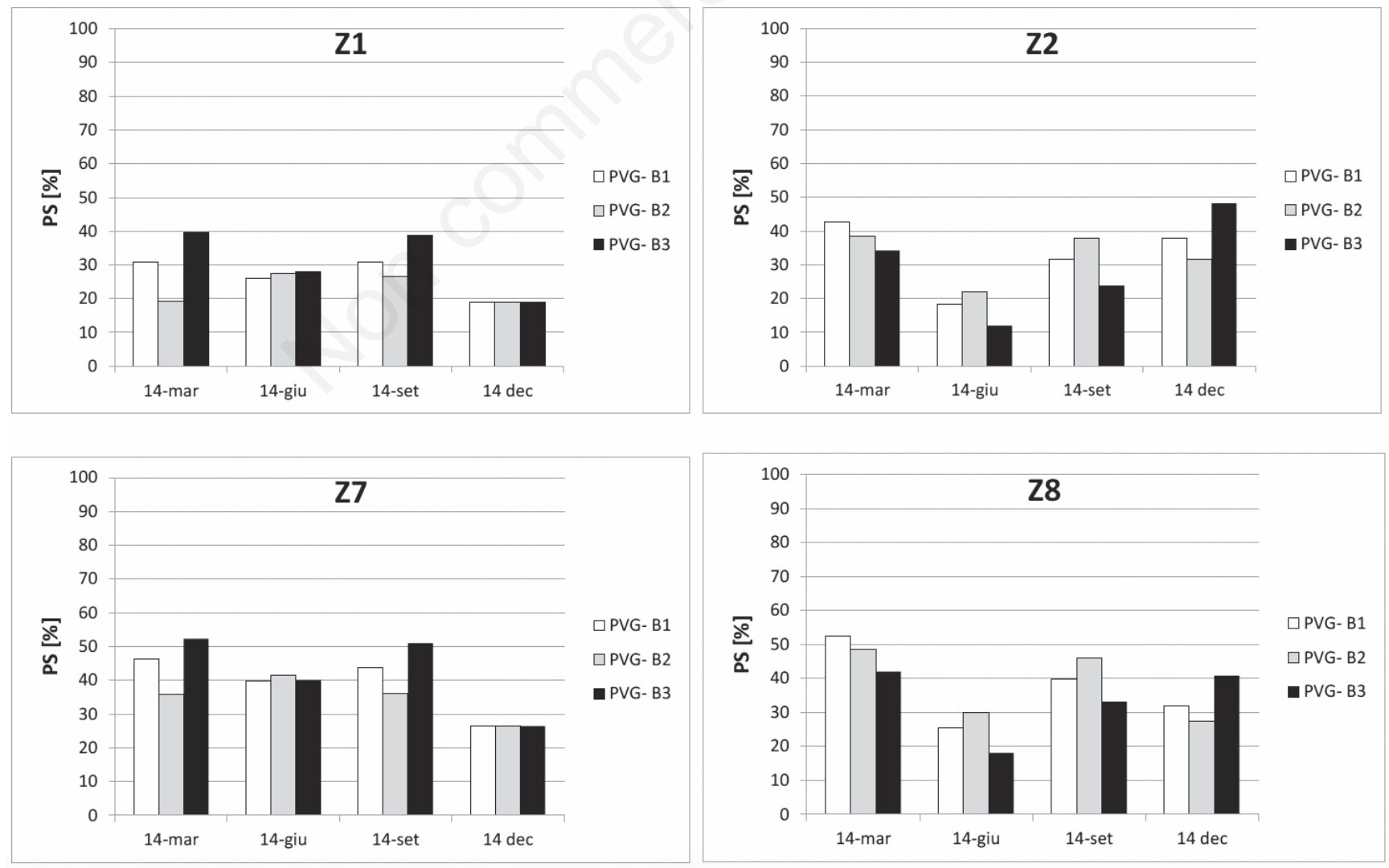

Figure 11. Percentage shaded (PS) in zones Z1-Z2 (west) Z7-Z8 (east) of greenhouses PVG- B1, PVG- B2, PVG- B3 (CR=20\%) in four representative days from 8.00 a.m. to 17.00 p.m. 
September. For each tested greenhouse, differences of PS are proportional to the covering ratio (Figure 8): i) G- A (CR=0\%): $\mathrm{PS}_{\mathrm{dec}}=19 \%$; $\mathrm{PS}_{\mathrm{sept}}=24 \% ; \Delta \mathrm{PS}=24-19=5 \%$; ii) PVG- B (CR=20\%): $\mathrm{PS}_{\mathrm{dec}}=27 \%$; $\mathrm{PS}_{\mathrm{mar}}=41 \% ; \Delta \mathrm{PS}=41-27=14 \%$; iii) PVG- C (CR=30\%): $\mathrm{PS}_{\mathrm{dec}}=29 \%$; $\mathrm{PS}_{\mathrm{sept}}=49 \% ; \Delta \mathrm{PS}=49-29=20 \%$; iv) PVG- D $(\mathrm{CR}=50 \%): \mathrm{PS}_{\mathrm{dec}}=33 \%$; $\mathrm{PS}_{\text {mar }}=62 \% ; \Delta \mathrm{PS}=62-33=29 \%$.

The distribution of shading percentage on the different zones of the reference plane is more complex with an high variability of results (Figures 9 and 10) passing, for instance in December, from PS=4\%, calculated in Z3 for all tested greenhouses, to $\mathrm{PS}=84 \%$ calculated in $\mathrm{Z} 6$ of PVG- D (Figure 10).

In all simulations, PS is proportional to the CR of the model, except for some calculations in which the PS of PVG- B is higher than the PVG$\mathrm{C}$ one (Figures 9 and 10). These results, apparently not coherent, are due to the fact that PVG- B results are the average of PVG- B1, PVG- B2 and PVG- B3 calculated values. Consequently, due to the extreme variability of these results (Figures 11 and 12), their average values are not always representative of the global behaviour of PVG- B (Figures 9 and 10). On the contrary of daylight analysis-in which only diffuse component is taken into account-insolation analysis highlighted how strongly PV panels layout on the roof affected the PS distribution on different zones on the reference plane. Extreme values were calculated in Z4 on march 14: PVG- B3 showed the highest value of PS=91\%, while PVG- B2 was characterised by $\mathrm{PS}=23 \%$ (Figure 11). Figures 11 and 12 show how difficult - defined the covering ratio $(\mathrm{CR}=20 \%)$ - is to predict what is the PV panels distribution which optimise the performances of the greenhouse. Indeed, while in zone Z3 the greenhouse PVG- B2 shows the lower values of shading percentage, in Z4, Z5, and Z6 it depends on the sun position (Figure 12).

\section{Agricultural performances}

In order to evaluate the agricultural performances of investigated PV greenhouses, the illuminance levels inside models were calculated. The design sky value of Rome virtual building site location, is $\mathrm{D}_{\text {Sky }}=7600$ lux (Ecotect, 2014). The illuminance level $\left(\mathrm{I}_{\mathrm{Lev}}\right)$ inside the PV greenhouses will be calculated multiplying DF by the design sky $\left(\mathrm{D}_{\text {Sky }}\right)$ value:

$\mathrm{I}_{\text {Lev }}=\mathrm{D}_{\text {Sky }} \mathrm{x} \mathrm{DF}$

The illuminance level represents the amount of lux inside the PV greenhouses- at ground level- for at least the $85 \%$ of the year. Calculated values (Eq. 5) will be compared with minimum lux requirements (LR) for high energy plants (HEP) and low energy plants (LEP): $\mathrm{LR}_{\text {HEPmin }}=3000$ lux; $\mathrm{LR}_{\mathrm{HEP} \min }=800$ lux (Gaastra, 1959). The yearly average value of $\mathrm{I}_{\text {Lev }}$ (Figure 13A) shows, that, at least in zones Z3 and Z4 the PV-D greenhouse is not suitable for HEP growing, while all investigated greenhouses seems to be suitable for LEP growing. However the average yearly value could not be significant due to the variability of factors which influence the illumination level, especially with regard to the sun position. Performing the same analysis on a single day at instance $14^{\text {th }}$ March minimum lux requirements for HEP are not reached by PVG- B1 in Z4 and Z6, PVG- B2 in Z6, PVG- B3 in Z4, PVG- D in Z4, Z5 and Z6, also for LEP are critical situation were calculated: PVG- B3 in Z4 and PVG- D in Z4 and Z5 (Figure 13B).
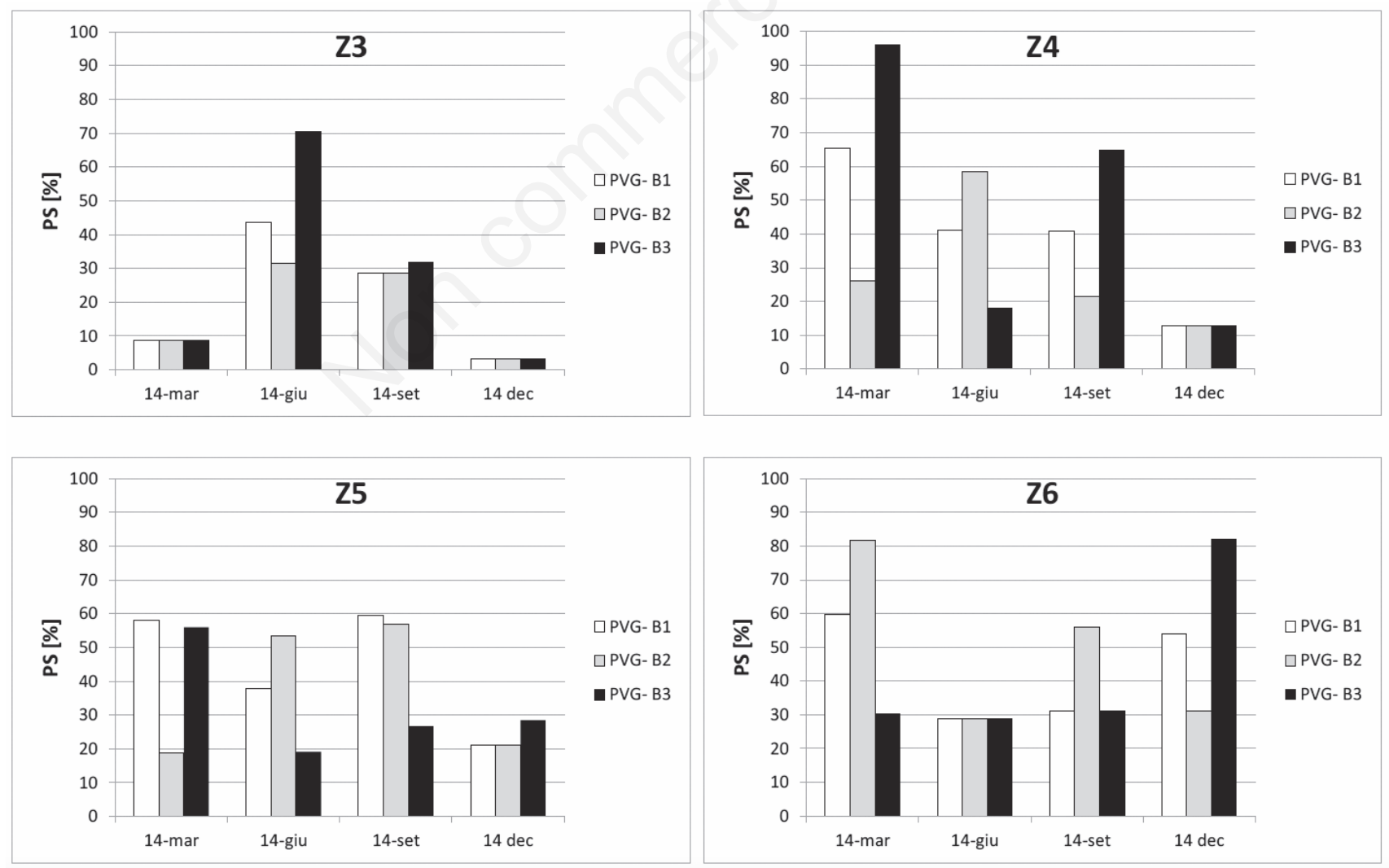

Figure 12. Percentage shaded (PS) in zones Z3 (south)-Z4-Z5-Z6 (north) of greenhouses PVG- B1, PVG- B2, PVG- B3 (CR=20\%) in four representative days from 8.00 a.m. to 17.00 p.m. 

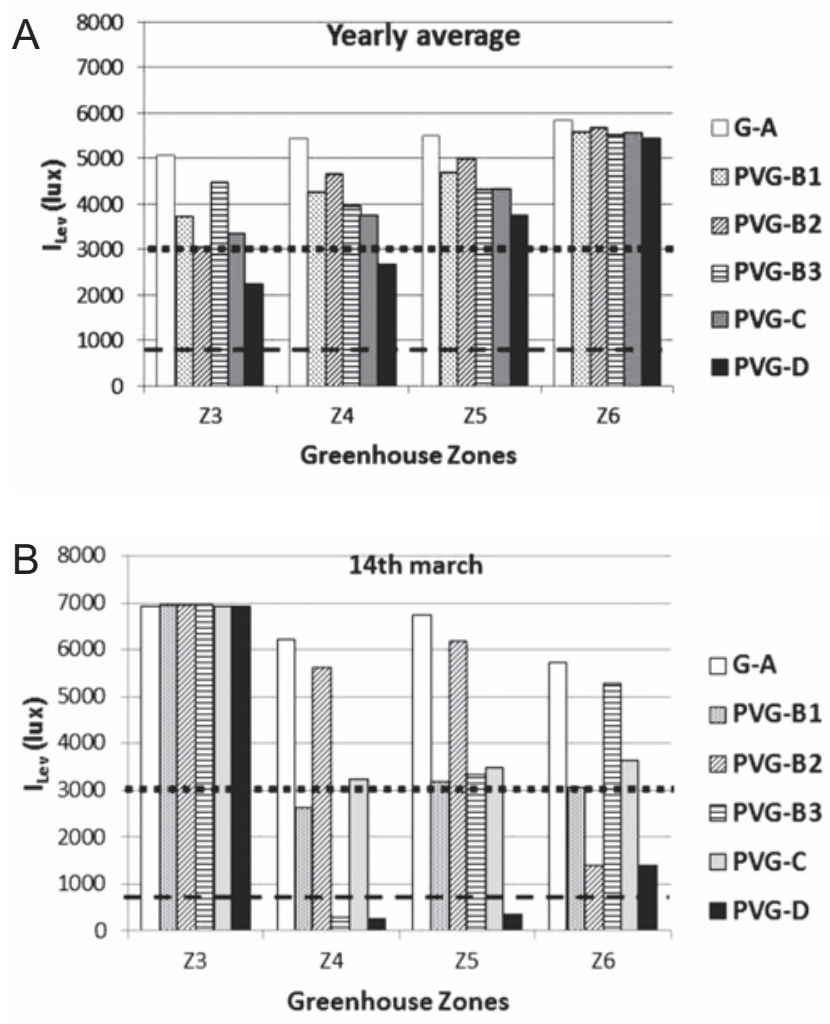

Figure 13. Yearly average values (A) and hourly average values on $14^{\text {th }}$ march (B) of illuminance level $\left(\mathrm{I}_{\mathrm{Lev}}\right)$ for investigated photovoltaic (PV) greenhouses in intermediate zones compared with threshold values of lux requirements for high energy plants $\mathrm{LR}_{\mathrm{HEP} \text { min }}=3000$ lux (dotted line) and low energy plants $\mathrm{LR}_{\mathrm{HEP} \min }=\mathbf{8 0 0}$ lux (dashed line).

\section{Conclusions}

Daylighting and insolation analysis showed similar results concerning the average value of the shading effect on the reference plane. In both cases, the shade distribution on the reference plane showed a linear correlation with the covering ratio.

Deepening the analysis to different zones of the greenhouse the insolation results, percentage exposed or shaded, seems to be more coherent with the real behavior than daylight distribution due to different sky model used in the analysis. The variability of shading effect is more complex to evaluate changing with the sun position, the zone inside the greenhouse and the configurations of photovoltaic panels on the roof of the structure. Results of this first study encourages to deepen in further analysis the effect of the geometric parameters of PV greenhouse and of the presence of cultivations inside and the correlation of simulation results with full scale measurements in order to calibrate the model.

\section{References}

Autodesk Ecotect Analysis. 2011. User reference manual. Available from: http://usa.autodesk.com/ecotect-analysis/
Badcock J., Lenzen M. 2010. Subsidies for electricity-generating technologies: a review. Ener. Policy 38:5038-47.

Beylot A., Payet J., Puech C., Adra N., Jacquin P., Blanc I., Beloin Saint Pierre D. 2011. Environmental impacts of large-scale grid-connected ground-mounted PV installations. World Renweble Energy Congress 2011, 8-13 May 2011, Linkoping, Sweden. Available from: http:/www.ep.liu.se/ecp/057/vol11/ecp057vol11.pdf

CIE (Commission International de l'Eclairage). 1996. CIE S003-1996. Spatial distribution of daylight - CIE standard overcast sky and clear sky. CIE Central Bureau, Vienna, Austria.

Ecotect. 2014. Archive site for Autodesk Ecotect Analysis educational resources, notes and tutorials. Available from: http://wiki.naturalfrequency.com/files/wiki/daylight/design-sky.swf

EPIA (European Photovoltaic Industries Association). 2014. Global market outlook for photovoltaics 2014-2018. Available from: http://www. epia.org/news/publications/ Accessed: May 2014.

Gaastra P. 1959. Photosynthesis of crop plants as influenced by light, carbon dioxide, temperature, and stomatal diffusion resistance. Meded. Landb. Hoogesch. Wageningen 59:1-68.

GSE (Gestore Servizi Energetici). 2013. Rapporto statistico fotovoltaico. Available from: http://www.gse.it/it/onto\%20Energia/Risultati\% 20incentivazione/Pages/default.aspx Accessed: April 2014.

Marucci A., Gusman A., Pagniello B., Cappuccini A. 2013. Limits and prospects of photovoltaic covers in Mediterranean greenhouses. J. Agric. Engine. 2013;44:1-8.

Poncet C., Muller M.M., Brun R., Fatnassi H. 2012. Photovoltaic greenhouses, non-sense or a real opportunity for the greenhouse systems?. Acta Hort. 927:75-9.

Sarasa-Maestro C.J., Dufo-López R., Bernal-Agustín J.L. 2013. Photovoltaic remuneration policies in the European Union. Ener. Policy 55:317-28.

Schettini E., De Salvador F.R., Scarascia-Mugnozza G., Vox G. 2011. Radiometric properties of photoselective and photoluminescent greenhouse plastic films and their effects on peach and cherry tree growth. J. Hort. Sci. Biotechnol. 86:79-83.

Taylor R. 2014. The potential ecological impacts of ground-mounted photovoltaic solar panels in the UK. Available from: http://www.bsgecology.com/wp-content/uploads/2014/02/Solar-panels-and-wildlifereview_RT_FINAL_140109.pdf

Tregenza P.R., Waters, I.M. 1983. Daylight coefficients. Light. Res. Technol. 15:65-71.

Tregenza P.R. 1986. Measured and calculated frequency distributions of daylight illuminance. Light. Res. Technol. 18:71-4.

Tudisca S., Di Trapani A.M., Sgroi F., Testa R., Squatrito R. 2013. Assessment of Italian energy policy through the study of a photovoltaic investment on greenhouse. Afr. J. Agric. Res. 8:3089-96.

Yano A., Onoe M., Nakata J. 2014. Prototype semi-transparent photovoltaic modules for greenhouse roof applications. Biosyst. Engine. 122:62-73.

Vieri S. 2012. Agricoltura settore multifunzionale allo sviluppo. Edagricole, Bologna, Italy.

Vox G., Schettini E., Lisi Cervone A., Anifantis A. 2008. Solar thermal collectors for greenhouse heating. Acta Hortic. 801:787-94.

Vox G., Teitel M., Pardossi A., Minuto A., Tinivella F., Schettini E. 2010. Sustainable greenhouse systems. In: A. Salazar and I. Rios (eds.), Sustainable agriculture: technology, planning and management. Nova Science Publishers, Inc., New York, NY, USA, pp 1-80. 